M.G. Chorzepa, et al., Int. J. of Safety and Security Eng., Vol. 6, No. 1 (2016) 10-18

\title{
HURRICANE VULNERABILITY OF COASTAL BRIDGES USING MULTIPLE ENVIRONMENTAL PARAMETERS
}

\author{
M.G. CHORZEPA, A. SAEIDPOUR, J.K. CHRISTIAN, \& S.A. DURHAM \\ The University of Georgia, USA
}

\begin{abstract}
Hurricanes and other severe storms have proven themselves to be one of the major threats to transportation assets throughout the world, particularly to bridges located along coastal areas. Bridges as key components of transportation networks have shown to be vulnerable to hurricane-induced wave and surge forces. A large number of bridges along the U.S. Gulf coast suffered severe damage from recent hurricanes. Current risk-assessment practices include the fragility analysis of bridges based on a single hazard intensity parameter such as peak ground acceleration. However, this study investigates the vulnerability of highway bridges against hurricanes for multiple hazard parameters, not including the risk of substructure failure due to scour and/or erosion. The proposed hurricane vulnerability assessment methodology is applied to bridges along the surge-prone coastal regions of the state of Georgia. The surge-prone region is identified by the USGS SLOSH maps, and vulnerable bridges are selected based on the available NBI database. Nonlinear bridge models have been developed to apply a time history of wave loading as a function of the wind speed and storm water depth. Different combinations of bridge geometric and material parameters are generated to develop meta-models which cover a wide range of bridge configurations and wave/surge loads. This study yields a fragility function which describes the probability of failure for vulnerable bridges in terms of two environmental parameters: wind speed and storm water depth. The findings of this study will ultimately be beneficial to policy makers prioritizing recovery efforts and allocation of essential resources.
\end{abstract}

Keywords: bridge, environmental parameters, fragility, Hurricane, metamodel, surge, SVM, vulnerability, wave.

\section{INTRODUCTION}

Hurricanes and severe storms have proven themselves to be one of the major threats to transportation assets throughout the world, particularly to bridges located along the coastlines. Past events have clearly demonstrated that the economic and social impacts to the community are excruciating and unsustainable [1,2]. Any loss of functionality in transportation networks will hinder the post-event emergency services and recovery efforts in the near term and will lead to slow economic and social development of affected regions in the long run. It has been estimated that there are approximately 36,000 bridges within 15 nautical miles of the U.S. coasts, out of which more than 1,000 bridges remain susceptible to similar damage [3]. A large number of bridges along the U.S. Gulf coast suffered severe damage during recent hurricanes such as Ike, Ivan, Katrina, and Rita [4]. These events have raised a national awareness of infrastructure resilience and reliability of transportation networks vulnerable to severe weather events and climate change. 


\subsection{Fragility analysis of structures}

Generally, in assessing risks in civil engineering applications, fragility analysis methods are used to assess the reliability or vulnerability of infrastructure, including bridges, subjected to natural hazards such as hurricanes and earthquakes. Reliability analysis methods used in vulnerability assessment of civil infrastructure are generally intended to provide risk-based decision making considering all aleatory variabilities and epistemic uncertainties associated with structural response and hazard intensity parameters such as peak ground accelerations in the event of earthquakes or wind speeds during severe storms.

The fragility analysis method is one of the reliability models which describe the probability of demand exceeding the capacity conditioned on a set of hazard and structural parameters. Fragility analyses of bridges subjected to various hazards have been extensively studied in recent years [5-7]. However, there are limited studies conducted on hurricane risks [8-11]. Furthermore, the fragility analysis is typically performed for a group of bridges with similar structural properties (referred to as bridges classes) and generally conditioned on a single hazard intensity measure (IM) such as peak ground acceleration. That is, the probability of structural damage is not traditionally evaluated as a direct function of bridge parameters. This study introduces an innovative metamodeling approach for parameterized fragility analysis of bridges under hurricane-induced wave forces. In this study, two new IMs, the peak 1-minute wind speed at the standard height of $10 \mathrm{~m}$ over unobstructed area $\left(\boldsymbol{U}_{\mathbf{1} \text { min }}\right)$ and storm water depth at the bridge location $\left(\boldsymbol{d}_{\boldsymbol{s}}\right)$, are considered at once. This method is implemented for a risk analysis of coastal bridges along the Georgia coastline.

\subsection{Hurricane-induced wave and surge forces}

Most of the bridges severely damaged during recent hurricanes are simply supported concrete bridges which either lacked vertical or horizontal restraints. For instance, some had poor connection details between the substructure and superstructure [12]. Generally, bridge failures during hurricane events are primarily attributed to deck unseating due to uplifting or lateral loads imposed by storm surge and wave action $[13,14]$. Although the effect of wave and surge forces on offshore structures has been extensively addressed in the literature [15-18], little attention had been given to susceptibility of bridges to these forces.

Marin and Sheppard developed equations to predict wave forces and moments on bridge superstructure by modifying Kaplan's equations [19]. In this study, the drag and inertia coefficients and slamming force parameters were empirically determined. The results of this research have been adopted into the AASHTO's ‘Guide Specification for Bridges Vulnerable to Coastal Storms' [20]. The equations provided by the AASHTO guide are used in this study to derive wave parameters and determine magnitudes of wave forces and moments.

\subsection{Hazard intensity parameters}

Fragility functions are conditioned on hazard IMs to generate a fragility surface to represent the probability of bridge failure. The fragility surfaces are dependent on two hazard intensity parameters: (1) the peak 1-minute wind speed and (2) storm water elevation at bridge location. In order to assess the hurricane vulnerability as a function of these two environmental parameters, the wave and surge parameters need to be derived by a function of the two parameters. In three-dimensional space, a rectangular mesh grid on the $\mathrm{X}-\mathrm{Y}$ horizontal plane represents a hazard intensity plane, and each node of this grid corresponds to a particular combination of 
hazard intensity parameters (or a hazard event). These hazard events are paired with each bridge model in a statistical test dataset to predict the response and probability of failure.

\section{HURRICANE VULNERABILITY ASSESSMENT}

The proposed parameterized fragility assessment of bridges against hurricane hazards consists of two hazard intensity parameters and bridge (geometrical and material) parameters to develop a meta-model by using a machine learning method. It is hypothesized that the proposed approach can be applied to a reliability assessment of bridges in any hurricane prone regions although the vulnerability analysis of one class of bridges (e.g., reinforced concrete girders/deck on concrete piles) in the Georgia coast is illustrated in this paper. Furthermore, the assessment technique may be applicable for other structural and hazard types. Utilizing metamodels offers two main advantages over traditional methods. First, metamodels could significantly decrease the computational cost by removing the need for costly analysis to predict the component/system response. Second, upon receiving new information from field inspections or other sources, parameterized fragility estimates, derived by metamodels, are easily re-evaluated. It is proposed that the reliability of bridges is ultimately presented as a fragility surface which is a by-product of parameterized fragility functions derived by a metamodel that logically predicts the relations of input and output parameters, as well as by integrating over the failure domain to find the probability of failure.

\subsection{Methodology}

Contrary to the traditional fragility estimate [7,9,22-24], the probability of structural damage $(P)$ is evaluated by a parameterized fragility function conditioned on multiple $I M s$ and a set of bridge parameters $(X)$ as shown in eqn (1). It is referred to as 'parametrized' because the probability is dependent on structural and material parameters of bridges.

$$
P[\text { Demand }>\text { Capacity } \mid I M, X]
$$

The key to this parameterized fragility function lies in 'metamodels.' Metamodels, also referred to as surrogate models, are statistical models that can predict the outcome of output parameters given the input parameters. In the context of this study, metamodels predict the bridge response (failed/not failed) for hurricane loads. Once this surrogate is generated, it is able to predict structural response of any bridge, provided that the bridge parameters are within the range of the analyzed dataset.

The proposed vulnerability assessment method uses a group of supervised learning algorithms called 'classification methods' to obtain the response of coastal bridges for hurricane events. The binary classification techniques used in this study predict bridge performance. The zero value represents a failure, and the unity represents no failure. In this study, the vulnerability assessment procedure is mainly divided into three stages: (1) Design of experiment; (2) Selection of a meta-model with the least classification error; and (3) Fragility analysis. While numerous machine learning methods are available, this study focuses on a presentation of results from the Support Vector Machines (SVM).

\subsection{Design of statistical experiment}

A well-designed experiment minimizes the response variance while optimizing the computational cost. Thus, the dependent and independent parameters are defined to design a statistical 
experiment by defining the input and output variables. The independent variables represent (a) bridge parameters including geometric and material properties and (b) hazard IMs including wind speed and storm water elevation. The dependent variables represent the (c) force output (or demands) from the analysis of bridge samples. The force demands are compared to (d) the capacity of bridge components which are determined by using the bridge input parameters.

In this study, the predictor variables are bridge parameters $(X)$ and $I M s$ defined in eqn (1). It is essential to couple a wide range of bridge parameters with hazard intensity parameters to generate a sample dataset for a statistical experiment. Therefore, a probability distribution density function of each predictor variable is defined. The distribution represents a wide range of the predictor variables. The Latin Hypercube Sampling (LHS) method is used to divide each predictor's probability distribution function into the ' $n$ ' number of intervals, where the width of each interval is determined to give an equal probability of occurrence. Subsequently, a predictor value is arbitrarily selected from each interval and is paired with the other randomly selected predictor variables to generate the ' $n$ ' number of bridge samples.

\subsection{Quantifying the response of parameterized bridge models}

Each bridge model is constructed in OpenSees (the Open System for Earthquake Engineering) as shown in Fig. 1, using the input parameters including bridge parameters and hazard intensity parameters. A parameterized finite element model is developed in OpenSees. This program employs the tool command language (or TCL) which is a scripting language created to automatically build analysis models in terms of input parameters. The parameterized modeling in OpenSees allows the generation of bridge models with multiple variables without having to manually change the input variables for each bridge model. This is particularly important in connection with a multivariable-based reliability analysis where a significant number of models must be generated and analyzed, and the results must be saved for a reliability analysis.

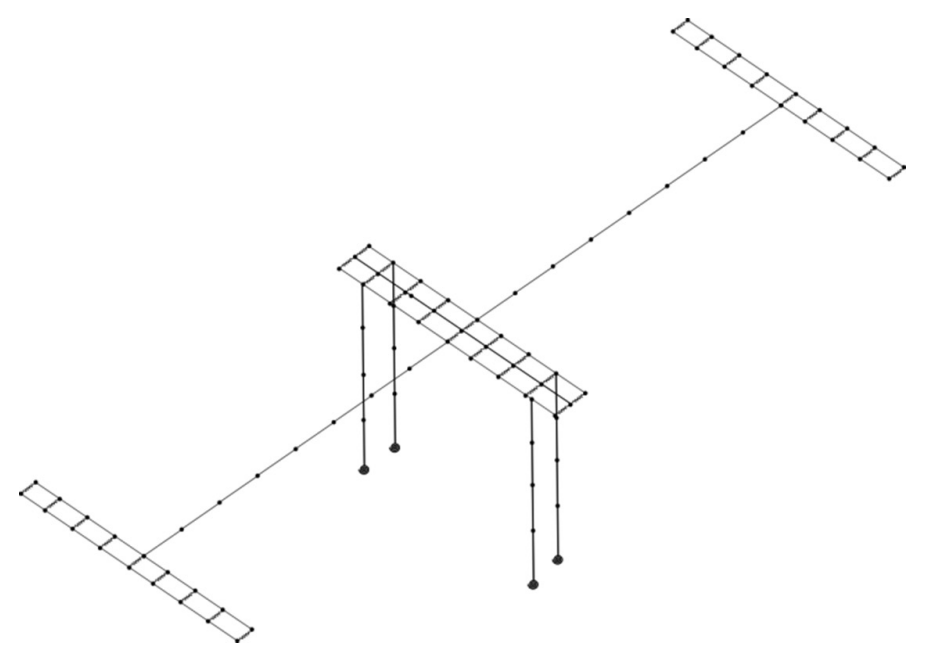

Figure 1: Parametrized bridge model (typical). 


\subsection{Support vector machines}

SVM are a class of supervised machine learning algorithms used for classification and regression. Generally in machine learning, the Gaussian radial basis function (RBF) kernel is a popular kernel function used in various kernelized learning algorithms. It is easy to consider that the method of kernel density estimation results in a probability density function for a test data set.

The SVM approach intends to find the optimum hyperplane which best separates a data set into two classes (e.g., bridge failed and not failed in this case) by maximizing the distance, so-called 'functional margin', between the nearest training data points and the hyperplane, as shown in Fig. 2. While this might not involve significant computational effort to divide these data points when they are linearly separable, the data points are not generally linearly dividable in the two-dimensional space. In this case, the data points are mapped and operated on in a higher dimensional space, and the optimum hyperplane is determined in the high-dimensional space as shown in Fig. 3. This process is called 'kernel-trick', and the functions which map the data points in a high-dimensional space are called kernel functions. In this study, three types of kernels (Linear, 3rd order Polynomial, and Gaussian RBF) have been used to find the minimum misclassification error. It is observed that the accuracy of the results highly depend on the selection of kernel functions. Therefore, $K$-fold cross validation was performed to assess the accuracy of the classification method, and the kernel function that yields the minimum classification error has been selected for fragility estimation.

\subsection{Fragility analysis}

Once the SVM model is developed for vulnerability prediction, it can be used for different representations of fragility curves in the case of interaction between two hazard (or environmental) parameters. In this study, a fragility surface is generated by using the SVM model. Fragility surfaces are conditioned on two IMs $\left(U_{1 \min }, d_{s}\right)$ and generally represent the probability of failure as a function of the IMs. This stage involves an evaluation of bridge response under numerous loading scenarios, and thus the metamodel as a by-product of the proposed machine learning process can be beneficial and efficient for determining vulnerability of bridges.

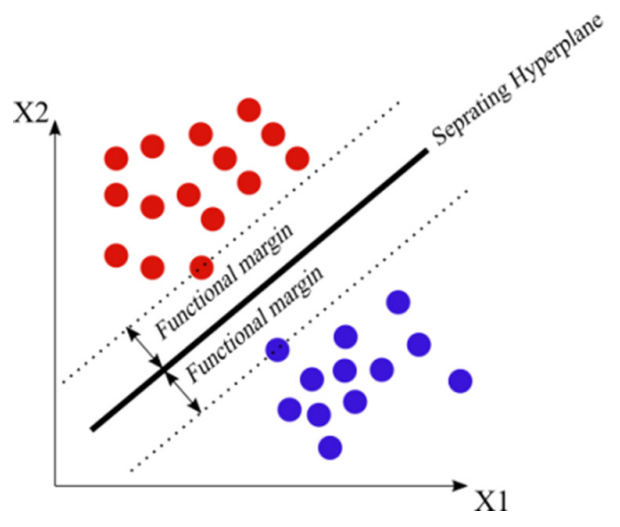

Figure 2: SVM classification for linearly separable data points. 


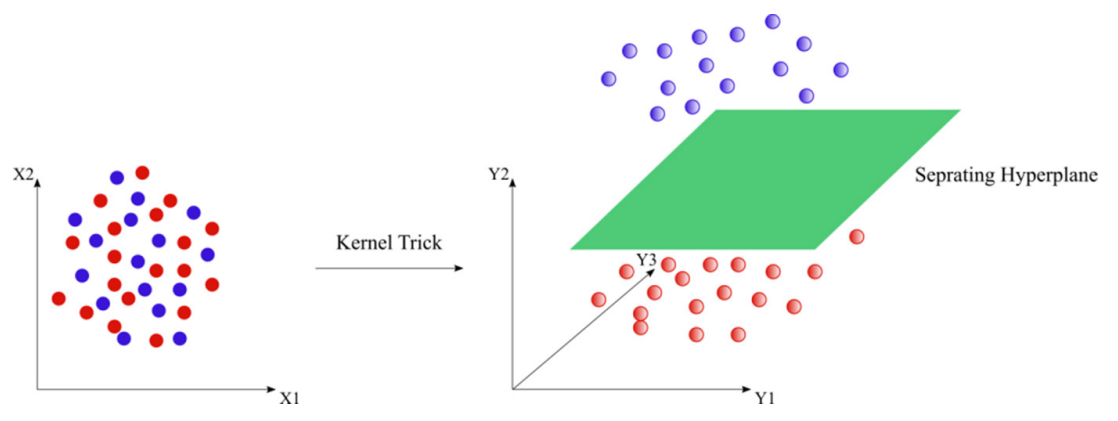

Figure 3: SVM classification for non-linearly separable data points.

The following four sub-steps are used to generate a fragility curve:

1. Generate $n$ realizations of a multivariate standard normal distribution using LHS $\left(x_{i}\right)$ :

$$
\phi(x)=\frac{1}{(2 \pi)^{n / 2}} e^{-\frac{1}{2} x^{T} x}
$$

2. Transform each $x_{i}$ into the original space of random variables: $y_{i}$

3. Input each $y_{i}$ into a metamodel to obtain the bridge response: $I_{i}=1,0$

2. Repeat the last step for each node of loading scenario grid and compute: $p_{i}$

$$
P_{i}=\frac{1}{n} \sum_{i=1}^{n} I_{i}
$$

\section{IMPLEMENTATION OF THE PROPOSED METAMODELING APPROACH}

This section contains an implementation of the proposed approach. The methodology presented in Section 2 is used to assess the vulnerability of Georgia coastal bridges for hurricanes. Although various climate data sources exist, the Sea, Lake and Overland Surges from Hurricanes (SLOSH) model available on the USGS website has been utilized to identify the likely flooded area by a Category 5 hurricane. The bridges located at the identified region are considered vulnerable to hurricanes in this study. Given the fact that the majority of the bridges in the studied region are composed of reinforced concrete girders on pile bents, this study focuses on evaluating the susceptibility of this class of bridges.

\subsection{Statistical sampling of bridge parameters}

As proposed, the LHS method is utilized to generate bridge samples such that a wide range of independent variables is included in the analysis. As discussed in Section 2.2, nonlinear finite element bridge models are developed in OpenSees to simulate the behavior of bridges subjected to hurricane-induced wave and surge forces.

\subsection{Metamodeling by using a support vector regression}

The metamodels are studied herein to define the input and output relations. The Support Vector regression method is used to develop a metamodel. Table 1 shows a so-called 'confusion 
Table 1: SVM confusion matrix.

\begin{tabular}{lll}
\hline Predicted\Test set & Failed & Not failed \\
\hline Failed & 644 & 95 \\
Not failed & 89 & 672 \\
\hline
\end{tabular}

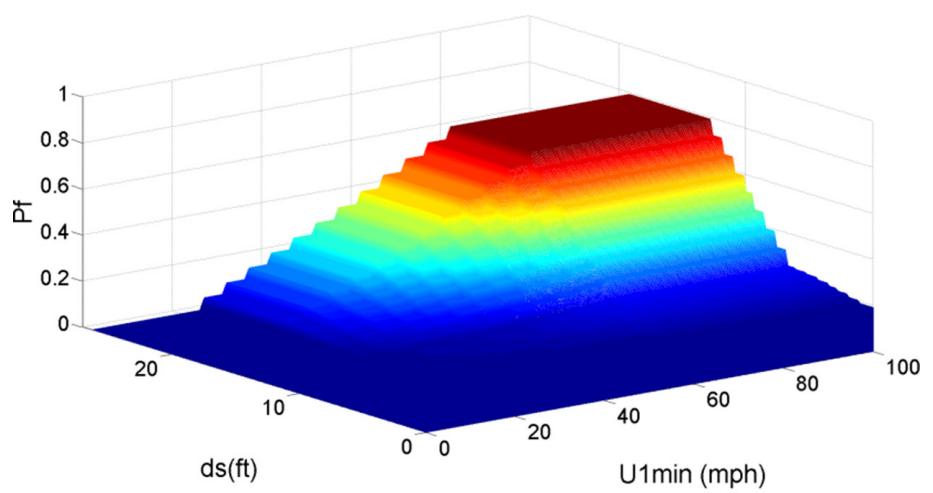

(a)

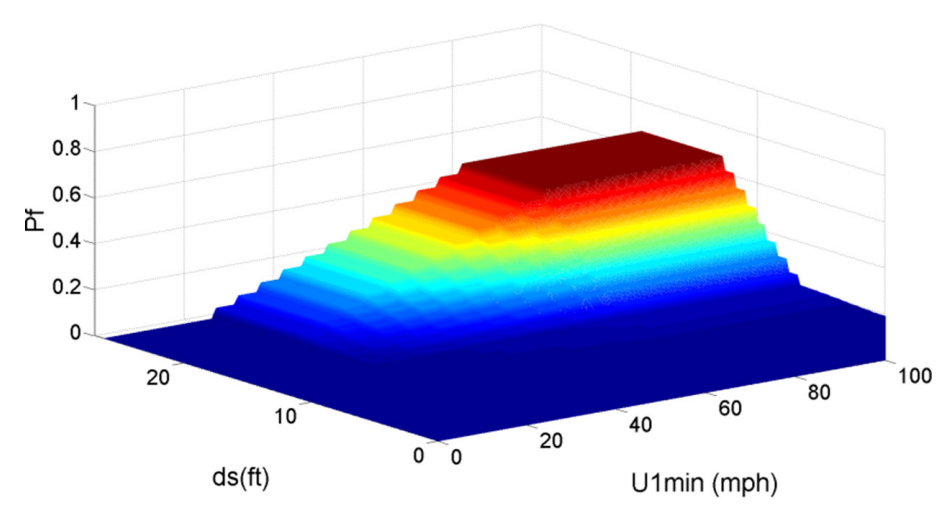

(b)

Figure 4: Fragility surfaces for selected bridge: (a) Dowel connection and (b) Anchor connection (note: $1 \mathrm{mph}=0.447 \mathrm{~m} / \mathrm{s} ; 1 \mathrm{ft}=0.305 \mathrm{~m}$ ).

matrix' for the SVM with a Gaussian RBF kernel function. Other kernel functions (i.e., linear and polynomials) yielded the probability of risks with less accuracy. Table 1 shows the confusion matrix. 184 samples out of 1,500 total samples are misclassified, which yields a misclassification error of $12.3 \%$. Thus, the overall accuracy is $87.7 \%$.

\subsection{Fragility surfaces}

One of the Georgia bridges from the test set is selected to illustrate how the proposed fragility analysis is completed. The cumulative probability of failure for each level of IMs has been calculated to obtain a fragility surface. Figure 4 includes a comparison of fragility surfaces generated for the selected bridge with two different deck-substructure connection types. Figure $4 \mathrm{a}$ shows the surface for the bridge with dowel connections and Fig. $4 \mathrm{~b}$ shows the same bridge 
with anchor bolt connections. As it is clear from two surface plots, the probability of failure (Pf) has increased with the increase of wind speed (U1 min) and storm water elevation (ds). It is also observed that the maximum probability of failure has decreased with the availability of anchor bolts. Dowels, unlike anchors, provide no vertical resistance against uplift forces. The only resisting force available in bridges with dowel connections is the deck self-weight, and thus they are more vulnerable. Similar comparisons are made for other variables used in this study.

\section{CONCLUSIONS}

The research is ongoing and aimed at improving the understanding of potential vulnerability of coastal bridges. Through a series of analytical studies performed herein and an extensive review of bridge drawings and climate data with subject matter experts, the study team plans to provide fragility estimates for coastal bridges under hurricane loading, which could ultimately assist authorities in prioritizing available resources for retrofit and maintenance of bridges based on their vulnerability. The proposed parameterized fragility assessment and development of metamodels to define the relationship between input and output parameters provide a framework by which sensitivity of bridge response, and its fragility can be investigated. Also, this framework has the ability to reassess the vulnerability as the new concerns emerge from routine inspections. The results of the proposed study have the potential for implementation at state department of transportation agencies by providing the framework and methodology for an effective hurricane vulnerability assessment for their coastal bridge assets.

\section{ACKNOWLEDGMENT}

The authors gratefully acknowledge the support provided for this research by the Georgia Department of Transportation under grant 15-01.

\section{REFERENCES}

[1] Douglass, S.L., Hughes, S., Rogers, S. \& Chen, Q., The impact of Hurricane Ivan on the coastal roads of Florida and Alabama. A preliminary report. Rep. to Coastal Transportation Engineering Research and Education Center, Mobile, AL, 2004.

[2] Padgett, J., DesRoches, R., Nielson, B., Yashinsky, M., Kwon, O.S., Burdette, N. \& Taver, E., Bridge damage and repair costs from Hurricane Katrina. Journal of Bridge Engineering, 13(1), pp. 6-14, 2008.

http://dx.doi.org/10.1061/(ASCE)1084-0702(2008)13:1(6)

[3] Douglass, S.L. \& Krolak, J., Highways in the Coastal Environment, FHWA, pp. 7-12, 2008.

[4] Gutierrez, C.M., Cresanti, R. \& Jeffrey, W.A., Performance of physical structures in Hurricane Katrina and Hurricane Rita: A reconnaissance report, NIST Technical Note, USA, 2006.

[5] Basöz, N. \& Kiremidjian, A.S., Development of empirical fragility curves for bridges. Proceedings of 5th U.S. Conference on Lifeline Earthquake Engineering, ASCE: Seatle, pp. 693-702, 1999.

[6] Karim, K.R. \& Yamazaki, F., A simplified method of constructing fragility curves for highway bridges. Earthquake Engineering \& Structural Dynamics, 32(10), pp. 1603-1626, 2003. http://dx.doi.org/10.1002/eqe.291

[7] Zhang, J. \& Huo, Y., Evaluating effectiveness and optimum design of isolation devices for highway bridges using the fragility function method. Engineering Structures, 31(8), pp. 1648-1660, 2009.

http://dx.doi.org/10.1016/j.engstruct.2009.02.017 
[8] Ataei, N., Vulnerability assessment of coastal bridges subjected to hurricane events, Doctoral dissertation, Rice University, Houston, 2013.

[9] Ataei, N. \& Padgett, J.E., Probabilistic modeling of bridge deck unseating during hurricane events. Journal of Bridge Engineering, 18(4), pp. 275-286, 2012.

[10] Ataei, N., Stearns, M. \& Padgett, J., Response sensitivity for probabilistic damage assessment of coastal bridges under surge and wave loading. Transportation Research Record: Journal of the Transportation Research Board, (2202), pp. 93-101, 2010.

[11] Kameshwar, S. \& Padgett, J.E., Multi-hazard risk assessment of highway bridges subjected to earthquake and hurricane hazards. Engineering Structures, 78, pp. 154-166, 2014.

http://dx.doi.org/10.1016/j.engstruct.2014.05.016

[12] Cauffman, S.A., Performance of Physical Structures in Hurricane Katrina \& Hurricane Rita: A Reconnaissance Report, DIANE Publishing, 2006.

[13] Robertson, I.N., Yim, S., Riggs, H.R. \& Young, Y.L., Coastal bridge performance during Hurricane Katrina. Proceedings of the Third International Conference on Structural Engineering, Mechanics and Computation, Elsevier: Cape Town, pp. 1864-1870, 2007.

[14] Stearns, M. \& Padgett, J.E., Impact of 2008 Hurricane Ike on bridge infrastructure in the Houston/Galveston region. Journal of Performance of Constructed Facilities, 26(4), pp. 441-452, 2011. http://dx.doi.org/10.1061/(ASCE)CF.1943-5509.0000213

[15] Bea, R.G., Iversen, R. \& Xu, T., Wave-in-deck forces on offshore platforms. Journal of Offshore Mechanics and Arctic Engineering, 123(1), pp. 10-21, 2001. http://dx.doi.org/10.1115/1.1342160

[16] Bea, R.G., Xu, T., Stear, J. \& Ramos, R., Wave forces on decks of offshore platforms. Journal of Waterway, Port, Coastal, and Ocean Engineering, 125(3), pp. 136-144, 1999. http://dx.doi.org/10.1061/(ASCE)0733-950X(1999)125:3(136)

[17] French, J.A., Wave uplift pressures on horizontal platforms, Technical report, California Institute of Technology, 1969.

[18] Kaplan, P., Murray, J.J. \& Yu, W.C., Theoretical analysis of wave impact forces on platform deck structures. Proceedings of the 14th International Conference on Offshore Mechanics \& Arctic Engineering, ASME: Copenhagen, pp. 190-198, 1995.

[19] Marin, J. \& Sheppard, D.M., Storm surge and wave loading on bridge superstructures. Proceedings of the Structures Congress 2009, ASCE: Austin, pp. 1-10, 2009.

[20] AASHTO, Guide Specifications for Bridges Vulnerable to Coastal Storms, USA, 2008.

[21] Padgett, J.E., Nielson, B.G. \& DesRoches, R., Selection of optimal intensity measures in probabilistic seismic demand models of highway bridge portfolios. Earthquake Engineering and Structural Dynamics, 37(5), pp. 711-726, 2008.

[22] Nielson, B.G. \& DesRoches, R., Seismic fragility methodology for highway bridges using a component level approach. Earthquake Engineering and Structural Dynamics, 36(6), pp. 823-829, 2007.

[23] Padgett, J.E. \& DesRoches, R., Methodology for the development of analytical fragility curves for retrofitted bridges. Earthquake Engineering and Structural Dynamics, 37(8), pp. 1157-1174, 2008. http://dx.doi.org/10.1002/eqe.801

[24] Tavares, D.H., Suescun, J.R., Paultre, P. \& Padgett, J.E., Seismic fragility of a highway bridge in quebec. Journal of Bridge Engineering, 18(11), pp. 1131-1139, 2013. http://dx.doi.org/10.1061/(ASCE)BE.1943-5592.0000471 